University of Wollongong

Research Online

Australian Institute for Innovative Materials -

Papers

Australian Institute for Innovative Materials

$1-1-2016$

Studies of poly(3,4-ethylenedioxythiophene) (PEDOT) films containing cationic Mn porphyrins. A loading-dependent demetalation of Mn(III)TPP in PEDOT (Mn(III)TPP=5,10,15,20-tetraphenylporphyrinato manganese(III))

Danijel Boskovic

University of Wollongong

Sivakumar Balakrishnan

CSIRO, University of Wollongong

Jun Chen

University of Wollongong, junc@uow.edu.au

Pawel W. Wagner

University of Wollongong, pawel@uow.edu.au

Gerhard F. Swiegers

University of Wollongong, swiegers@uow.edu.au

Follow this and additional works at: https://ro.uow.edu.au/aiimpapers

Part of the Engineering Commons, and the Physical Sciences and Mathematics Commons

Research Online is the open access institutional repository for the University of Wollongong. For further information contact the UOW Library: research-pubs@uow.edu.au 


\title{
Studies of poly(3,4-ethylenedioxythiophene) (PEDOT) films containing cationic Mn porphyrins. A loading-dependent demetalation of Mn(III)TPP in PEDOT (Mn(III)TPP=5,10,15,20-tetraphenylporphyrinato manganese(III))
}

\author{
Abstract \\ Thin films of vapor-phase polymerized PEDOT incorporating various cationic Mn porphyrins were \\ assessed for water oxidation catalysis under light illumination. Only Mn(III)TPP/PEDOT displayed a \\ notable photocurrent and this was, counter-intuitively, greatest at the lowest loading levels examined. \\ Studies revealed that a proportion of the Mn(III)TPP within the PEDOT became demetalated during \\ polymerization, leaving free and protonated TPP. Despite the presence of an excess of chemical oxidant \\ during the polymerization step, the $\mathrm{Mn}$ (III) ion was reduced - likely under the influence of light - to $\mathrm{Mn}$ (II), \\ which was labilized out of the film. Whereas PEDOT films loaded with anionic Mn porphyrins may be \\ active and selective water oxidation photocatalysts, their analogs containing cationic Mn porphyrins, like \\ Mn(III)TPP, are catalytically inert. \\ Disciplines \\ Engineering | Physical Sciences and Mathematics \\ Publication Details \\ Boskovic, D., Balakrishnan, S., Chen, J., Wagner, P. \& Swiegers, G. F. (2016). Studies of \\ poly(3,4-ethylenedioxythiophene) (PEDOT) films containing cationic Mn porphyrins. A loading-dependent \\ demetalation of Mn(III)TPP in PEDOT (Mn(III)TPP=5,10,15,20-tetraphenylporphyrinato manganese(III)). \\ Journal of Porphyrins and Phthalocyanines, 20 (12), 1463-1476.
}

This journal article is available at Research Online: https://ro.uow.edu.au/aiimpapers/2391 


\title{
Studies of poly(3,4,-ethylenedioxythiophene) (PEDOT) films containing cationic Mn porphyrins. A loading-dependent de- metallation of $\mathrm{Mn}(\mathrm{III}) \mathrm{TPP}$ in PEDOT (Mn(III)TPP=5,10,15,20- tetraphenylporphyrinato manganese(III))
}

\author{
Danijel Boskovic, Sivakumar Balakrishnan, Jun Chen, Pawel Wagner, and Gerhard \\ F. Swiegers
}

Intelligent Polymer Research Institute and ARC Centre of Excellence for Electromaterial Science, Innovation Campus, University of Wollongong, Wollongong, NSW 2522, Australia

Received date (to be automatically inserted after your manuscript is submitted)

Accepted date (to be automatically inserted after your manuscript is accepted)

\begin{abstract}
Thin films of vapour-phase polymerized PEDOT incorporating various cationic Mn porphyrins were assessed for water oxidation catalysis under light illumination. Only $\mathrm{Mn}(\mathrm{III}) \mathrm{TPP} / \mathrm{PEDOT}$ displayed a notable photocurrent and this was, counter-intuitively, greatest at the lowest loading levels examined. Studies revealed that a proportion of the Mn(III)TPP within the PEDOT became demetallated during polymerization, leaving free and protonated TPP. Despite the presence of an excess of chemical oxidant during the polymerization step, the $\mathrm{Mn}$ (III) ion was reduced - likely under the influence of light - to Mn(II), which was labilized out of the film. Whereas PEDOT films loaded with anionic Mn porphyrins may be active and selective water oxidation photocatalysts, their analogues containing cationic Mn porphyrins, like Mn(III)TPP, are catalytically inert.
\end{abstract}

KEYWORDS: PEDOT, de-metallation, Mn porphyrin, Light-induced, photocatalysis

*Correspondence to: Pawel Wagner, email: pawel@uow.edu.au, or Gerhard F. Swiegers, email: swiegers@uow.edu.au, tel: +61-2- 


\section{INTRODUCTION}

Mn-porphyrins have gained attention in recent years due to their potential utility in water oxidation catalysis. In previous articles we reported selective photocatalytic water oxidation by the conducting polymer composites poly(terthiophene) (PTTh) [1] and poly(3,4-ethylenedioxythiophene) (PEDOT), containing high levels of the anionic Mn(III) porphyrin 5,10,15,20-tetrakis(4-sulfonatophenyl)porphyrinato manganese (III) (MnTPPS) [2]. Composites of this type proved to be remarkably selective photocatalysts of water oxidation. In seawater they generated only oxygen gas, with no measurable chlorine formation detected [1]. Studies suggested that these effects derived from intermolecular catalysis involving Mn porphyrin pairs embedded within the conducting polymer support that were adventitiously closely proximate to each other, possibly within so-called H-aggregates in which the porphyrins are assembled in face-to-face arrangements [1,2]. Naruta and co-workers have previously demonstrated that closely proximate, eclipsed co-facial Mn porphyrins are effective catalysts of water oxidation, forming dioxygen from water in a 4-electron process [3-5]. In view of these findings, we were interested to study similar materials containing PEDOT embedded with Mn porphyrins that form cationic species in solution, including 5,10,15,20-tetraphenylporphyrinato manganese(III) $\left[\mathrm{MnTPP}^{+}\right]$('MnTPP') and 5,10,15,20-tetrakis(4-methylpyridinium)porphyrinato manganese (III) $\left[\mathrm{MnTMPyP}^{5+}\right]$ ('MnTMPyP') (Figure 1). The latter was also incorporated into PEDOT and studied in the form of the ion-pair [MnTPPS $]_{5}^{3-}\left[\mathrm{MnTMPyP}_{3}{ }^{5+}\right.$ ('MnTPPS+MnTMPyP') (Figure 1). The ion-pairing was utilised in an attempt to bring about co-facial aggregation within the PEDOT during deposition. PEDOT loaded with these Mn porphyrins did not exhibit a notable photocatalytic water oxidation effect. However, the MnTPP in PEDOT/MnTPP was found to undergo a remarkable, loading-dependent demetallation reaction that was likely light-induced and limited by the optical transparency of the PEDOT.

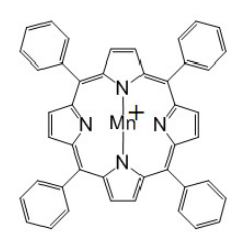

(a)

$\operatorname{MnTPP}^{+}$(='MnTPP')

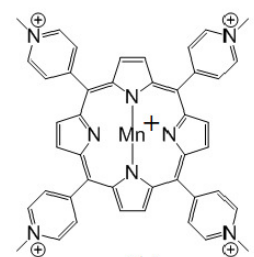

(b)

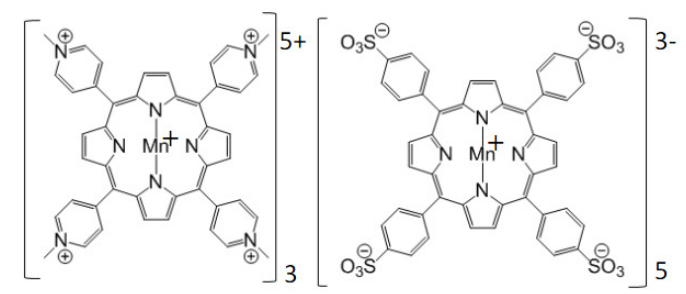

(c)

$[\text { MnTMPyP }]_{3}{ }^{5+}[\text { MnTPPS }]_{5}^{3-}{ }^{3=}$ MnTPPS+MnTMPyP')

Figure 1. Porphyrin species studied in this work: (a) 5,10,15,20-tetraphenylporphyrinato manganese(III) ('MnTPP'), (b) 5,10,15,20-tetrakis(4methylpyridinium)porphyrinato manganese(III) ('MnTMPyP'), and (c) 5,10,15,20-tetrakis(4-methylpyridinium)porphyrinato manganese(III) 5,10,15,20-tetrakis(4-sulfonatophenyl)porphyrinato manganese(III) ('MnTPPS+MnTMPYP').

\section{EXPERIMENTAL}

\section{Materials and methods}

The following materials were used as supplied: Fluorine doped tin oxide (FTO) slides (Zhuhai Kaivo Electronic Components Co.), glass microscope slides (Australia Optics Superstore), EDOT, pyridine (Thermo Fisher Scientific Australia), iron(III) p-toluenesulfonate (Fe(III)-pTS) (Sigma Aldrich), 5,10,15,20-tetraphenylporphyrin (TPP) (Sigma Aldrich Co.), acetone (Sigma Chemicals), ethanol (Sigma Chemicals), and sodium sulphate $\mathrm{Na}_{2} \mathrm{SO}_{4}$ (Aim Chemicals). De-ionized water was used in all experiments. 
Mn(III)TPP was prepared by modifications of literature procedures [6-8]. The final product was characterised by UV-Vis and its main absorbance peaks and their extinction coefficients were found to be in agreement with published data [9,10]. TMPyP and MnTMPyP were synthesized by modifications of literature procedures [6,11]. TMPyP was characterized by MALDI and UV-Vis and the results were found to be in agreement with literature data [11]. MnTMPyP in water was characterized by UV-Vis spectroscopy and its main absorbance peaks and their extinction coefficients were found to agree with published data [11]. TPPS and MnTPPS were prepared by modifications of a previously published procedure [9,13,14]. The absorbance peaks and their extinction coefficients for MnTPPS agreed with published data [12]. TPP $(0.1 \mathrm{M})$ was protonated by dissolution in dichloromethane, followed by the addition of a few drops of trifluoroacetic acid to the mixture to protonate the porphyrin. The solution was transferred to a quartz cuvette and the UV-Vis spectrum for the acidified species $\left(\mathrm{H}_{4} \mathrm{TPP}\right)^{2+}$ was recorded [9].

Elemental analysis was carried out by the Microanalytical Unit at the Australian National University Research School of Chemistry and the School of Chemistry at the University of Wollongong.

\section{Reduction of Mn(III)TPP to Mn(II)TPP}

Mn(III)TPP was reduced to Mn(II)TPP following a suggested method [15]. A solution of Mn(III)TPP (0.01 M) in ethanol was transferred to a UV-Vis quartz cuvette. The cuvette was covered with parafilm to avoid exposure to air, and a Pasteur pipette tip inserted to bubble Argon gas through the solution for $30 \mathrm{~min}$. A small amount of $\mathrm{NaBH}_{4}(10 \mathrm{mg})$ and $\mathrm{Na}_{2} \mathrm{~S}_{2} \mathrm{O}_{4}(10 \mathrm{mg})$ were added while the solution was bubbled with Ar gas. Care was taken not to expose the solution to air as oxygen readily oxidizes the porphyrin back to the $\mathrm{Mn}(\mathrm{III})$ state. After 5 min the cuvette was quickly transferred to the UV-Vis spectrometer, whilst maintaining an inert atmosphere, and a spectrum was recorded. The spectrum displayed the characteristic Soret Band, shifted from $466 \mathrm{~nm}\left(\mathrm{Mn}^{\mathrm{III}}\right)$ to $432 \mathrm{~nm}\left(\mathrm{Mn}^{\mathrm{II}}\right)$ [15]. A small quantity of degassed Milli-Q water $(0.5 \mathrm{~mL})$ was then added to the solution. This resulted in a partial shift of the Soret Band to $420 \mathrm{~nm}$, close to that of free TPP at $415 \mathrm{~nm}$, as well as a partial restoration of the characteristic TPP Q-bands at 514, 550, 590 and 645 nm.

\section{Preparation of porphyrin/PEDOT on FTO glass by vapour phase polymerization (VPP)}

Vapour phase polymerized (VPP) films of PEDOT with and without porphyrin, were prepared by conventional methods [16]. Solutions containing iron (III) p-toluenesulfonate hexahydrate (Fe-pTS) oxidant (85 mg, $1.25 \times 10^{-4} \mathrm{M}$, $10 \%$ by mass) and pyridine at 0.5 molar equivalent of the oxidant $\left(5 \mu \mathrm{L}, 0.625 \times 10^{-4} \mathrm{M}\right)$, combined in $80 \%$ ethanol/water $(1 \mathrm{~mL})$, were prepared. Pyridine was added to the oxidant solution to impede an unwanted, competing polymerization process [16,17]. The concentration of the Mn porphyrin present in the polymerization mixture was varied in order to study the effect of porphyrin loading on the photocatalytic performance on the films prepared. The Mn porphyrins MnTPP, MnTMPyP and MnTPPS+MnTMPyP were incorporated in their respective samples in loadings of: (i) $1 \mathrm{mg} / \mathrm{mL}$, (ii) $2 \mathrm{mg} / \mathrm{mL}$, or (iii) $3 \mathrm{mg} / \mathrm{mL}$. In the case of the MnTPPS+MnTMPyP mixture, both porphyrins were added in an ca. 1:1 ratio with the concentration used to identify the mixture being the combined concentration of porphyrin species in solution. This was done before the addition of Fe-pTS and pyridine to the mixture to ensure that the porphyrin dissolved completely.

Fluorine doped tin oxide (FTO) glass was cut into rectangles with the dimensions of $2.7 \times 5.5 \mathrm{~cm}$. A line was drawn $1 \mathrm{~cm}$ from the edge on the long side. Non-conductive (microscope) glass slides were also cut to $5.5 \mathrm{~cm}$ length and cleaned with the FTO slides in acetone and then milli-Q water for 20 min each in a sonication bath. Each slide was rinsed with milli-Q water and dried with pressurized air before UV-ozone treatment for 20 min.

Vacuum distilled 3,4-ethylenedioxythiophene (EDOT) monomer $(0.4 \mathrm{ml})$ was thawed and inserted into a sealed conical flask embedded with an alligator clip to hold an FTO glass sample above the liquid. The oxidant/porphyrin 
solutions were filtered through $0.2 \mu \mathrm{m}$ syringe filters before being spin-coated onto the slides (1000 rpm, $15 \mathrm{sec}, 0.2$ $\mathrm{mL}$ ) followed by drying at $80{ }^{\circ} \mathrm{C}$ in air for $5 \mathrm{~min}$. To limit the area for polymerization to precise dimensions, the oxidant film was carefully swabbed with a cotton tip and ethanol from the $1 \mathrm{~cm}$ line marking to create a clean zone above the film.

The samples were then inserted into the conical flask and left to polymerize in air at $60{ }^{\circ} \mathrm{C}$ for 40 min. Samples were thereafter left to dry in air at room temperature overnight. The resulting films comprised of PEDOT (control), MnTPP/PEDOT, MnTMPyP/PEDOT or MnTPPS+MnTMPyP/PEDOT (Figure S1). Each was washed by submerging it in Milli-Q water for $30 \mathrm{~s}$, then letting the liquid run down by holding the slide upright on a paper towel. Each sample was thereafter dried in an oven for $30 \mathrm{~min}$ at $60{ }^{\circ} \mathrm{C}$ under air.

A copper wire was attached to the FTO surface with conductive silver paint and epoxy resin. When the silver paste was fully solidified, epoxy glue was used to cover the contact area of the wire as well as any exposed clean FTO glass surface. The FTO glass slides with PEDOT film were cut in half and each fashioned into a duplicate working sample. The surface area of film was measured for every sample and the current data converted to current density to eliminate the influence of size variations on the overall results.

\section{Thickness and conductivity measurements}

The thickness and conductivity of each sample was measured using a Dektak profilometer and four-point probe. The polymer film samples were prepared on both FTO glass and microscope slide glass in parallel. Microscope slide glass was used for thickness and conductivity testing of the samples (Table S1).

\section{Electrochemical testing}

All electrochemical measurements were carried out in $0.1 \mathrm{M} \mathrm{Na}_{2} \mathrm{SO}_{4}$ on an EDAQ466 potentiostat. Linear sweep voltammograms were performed at a scan rate of $5 \mathrm{mV} / \mathrm{s}$. The electrochemical cell employed comprised of a rectangular chamber with fixed positions for the working electrode, reference electrode $(\mathrm{Ag} / \mathrm{AgCl})$ and counter electrode $(\mathrm{Pt}$ mesh; ca. $1.0 \times 1.5 \mathrm{~cm})$. The distance between the working and counter-electrode was $25 \mathrm{~mm}$.

The PEDOT and Mn porphyrin/PEDOT samples were subjected to electrochemical testing in a cell filled with $\mathrm{Na}_{2} \mathrm{SO}_{4}(0.1 \mathrm{M})$ that had been degassed with $\mathrm{N}_{2}$ gas while stirring for $1 \mathrm{~h}$. A SoLux daylight MR16 halogen light bulb $\left(12 \mathrm{~V}, 50 \mathrm{~W}, 24^{\circ}\right.$; ca. 0.25 sun intensity) was used with a stable output range of $275-750 \mathrm{~nm}$. The lamp only approximated sunlight conditions. The light was passed through a $3 \mathrm{~mm}$ glass filter to remove the infra-red component, before reaching the sample. The cut-off filter blocked all wavelengths above $700 \mathrm{~nm}$.

Before testing, cyclic voltammetry $(\mathrm{CV})$ was performed on the film for 20 cycles at $10 \mathrm{mV} / \mathrm{s}$ in order to stabilise the film. Linear sweep voltammograms (LSVs) were then performed over the range of $0.0-0.7 \mathrm{~V}$ at $5 \mathrm{mV} / \mathrm{sec}$. Voltages beyond $0.7 \mathrm{~V}$ ( vs $\mathrm{Ag} / \mathrm{AgCl}$ ) were not studied in order to avoid oxidative damage to the film. In a typical experiment, 5 sweeps were done in the dark followed by 3 sweeps under illumination. The last of the LSV sweeps with and without illumination were considered as data (Figure 2). The measured currents were converted into current density by dividing by the geometric area of the film.

Following the LSV measurements, each sample was tested by chronoamperometry (CA) at potentials of $0.6 \mathrm{~V}, 0.65$ $\mathrm{V}$ and $0.7 \mathrm{~V}$ (vs $\mathrm{Ag} / \mathrm{AgCl})$. In a typical experiment the chosen voltage was applied to the film for $1 \mathrm{~h}$ without illumination to equilibrate the baseline current. The light illumination was then turned on and the resulting photocurrent measured for $10 \mathrm{~min}$. The data in Figure 3 were taken from 1 min before illumination to 1 min after illumination. The data was normalized by subtracting the baseline before illumination and converted to current density.

\section{Electrochemical testing with collection and analysis of gases produced}


Photocurrent testing of MnTPP/PEDOT samples with simultaneous collection and analysis of the gases produced was done using a specialized apparatus. The apparatus consisted of a sealed glass electrochemical cell containing the working electrode sample, a $\mathrm{Ag} / \mathrm{AgCl}$ reference electrode and a $\mathrm{Pt}$ mesh counter electrode (Figure S2). The cell was filled with $\mathrm{Na}_{2} \mathrm{SO}_{4}$ electrolyte $(0.1 \mathrm{M})$ and the electrolyte continuously bubbled with Ar gas prior to and during the experiment. The gas outlet of the cell was connected via copper tubing and a sample loop, to a dedicated Shimadzu GC8A gas chromatograph, which was used to determine the constituents of the gas flowing through the cell. The Ar gas provided the carrier gas for a connected gas chromatography unit. Prior to each experiment, the cell was purged overnight with Ar and the gas coming out of the cell was shown to contain nothing other than Ar.

The electrodes were connected to a $\mathrm{CHI}$ potentiostat and the sample was poised at $0.7 \mathrm{~V}$ vs $\mathrm{Ag} / \mathrm{AgCl}$ in $0.1 \mathrm{M}$ $\mathrm{Na}_{2} \mathrm{SO}_{4}$ for $1 \mathrm{~h}$, then illuminated with a Newport solar simulator equipped with a $1000 \mathrm{~W}$ Xenon lamp and a AM 1.5 filter while maintaining a fixed bias. Prior to turning on the potentiostat and, later, the lamp, the carrier gas passing through the cell was again tested and shown to contain only Ar with no trace of another gas present.

After $4.7 \mathrm{~h}$ of testing with the Xenon lamp on, the carrier gas passing through the cell was analyzed using the attached gas chromatograph and the results plotted over $30 \mathrm{~min}$ of elution time. Testing after illumination gave a qualitative measure of the gases produced by photoelectrochemical activity of the sample.

\section{RESULTS AND DISCUSSION}

\section{Mn porphyrin/PEDOT films}

Electrode films were prepared by vapour phase polymerization (VPP) of monomeric 3,4-ethylenedioxythiophene (EDOT) into the conducting polymer PEDOT, on FTO glass [16]. VPP employs iron (III) p-toluenesulfonate hexahydrate (Fe-pTS) as the oxidant that drives polymerisation. Unlike other methods of polymerization, VPP allows the in-situ formation of polymeric PEDOT containing an embedded chemical species that does not act as a counter-ion. The high density of films produced by VPP allow for the immobilization of species that do not have a high binding affinity for the PEDOT polymer.

The Mn porphyrins were incorporated in the PEDOT film in low to very low loading levels in order to: (i) examine the effect of increasing the loadings on potential photocatalytic properties, (ii) to illuminate fundamental interactions between the PEDOT and the Mn porphyrins, and (iii) to provide for accurate photocurrent comparisons between samples. In the case of the above cationic species, low loading levels were also intended to minimize repulsive interactions with the PEDOT polymer, which forms a positively charged backbone when it is in its conducting, oxidized state.

Vapour phase polymerization of PEDOT yielded thin films on glass, which were typically coloured blue (for PEDOT alone) or green (when a Mn porphyrin was present) (Figure S1). Four types of film were prepared: (i) PEDOT alone (control), (ii) MnTPP/PEDOT, (iii) MnTMPyP/PEDOT, and (iv) MnTPPS+MnTMPyP/PEDOT. The films exhibited thicknesses on the order of $\sim 0.1 \mu \mathrm{m}$ and conductivities of 100-300 S cm${ }^{-1}$ (Table S1) which were modest compared to values of $800 \mathrm{~S} \mathrm{~cm}^{-1}$ that have been reported in the scientific literature [16-22].

A key aim of this work was to establish whether the Mn/PEDOT films displayed cooperative catalysis involving pairs of proximate Mn porphyrins within the film. In previous studies involving PEDOT loaded with anionic MnTPPS, ${ }^{2}$ the observed catalytic photocurrents increased with increases in the loading level of the Mn porphyrin in the PEDOT, suggesting a cooperative catalytic mechanism of this type. In the present work we wished to establish whether such a relationship also existed in PEDOT films containing the cationic Mn porphyrins above. 

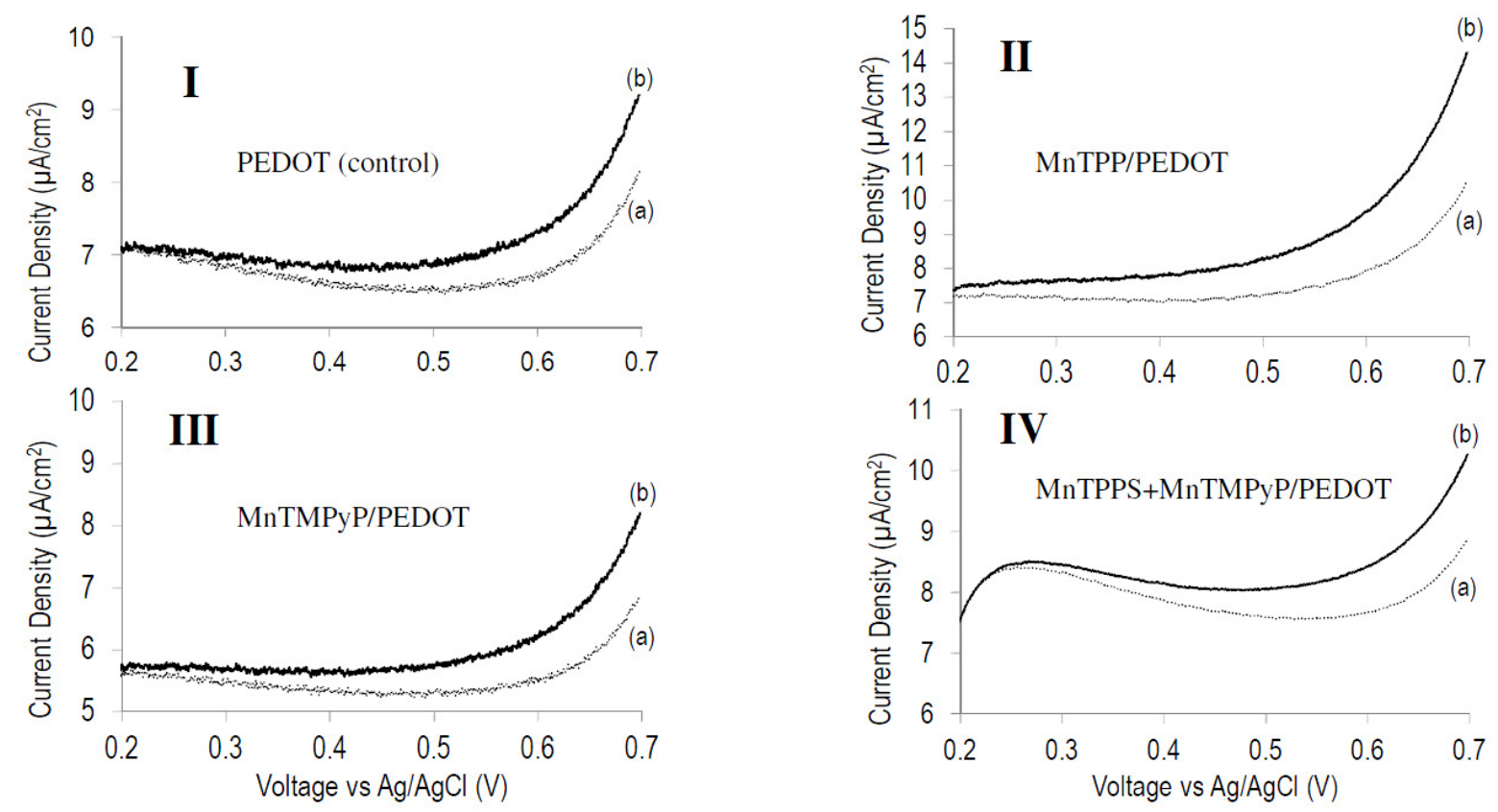

Figure 2. Linear sweep voltammograms in $0.1 \mathrm{M} \mathrm{Na} 2 \mathrm{SO}_{4}$ solution, under (a) dark conditions and (b) with light illumination, of: (I) PEDOT (control), (II) MnTPP/PEDOT, (III) MnTMPyP/PEDOT, (IV) MnTPPS+MnTMPyP/PEDOT. All Mn porphyrins were present in PEDOT polymerization solutions in loadings of $2 \mathrm{mg} / \mathrm{mL}$. Scan rate: $5 \mathrm{mV} / \mathrm{s}$.
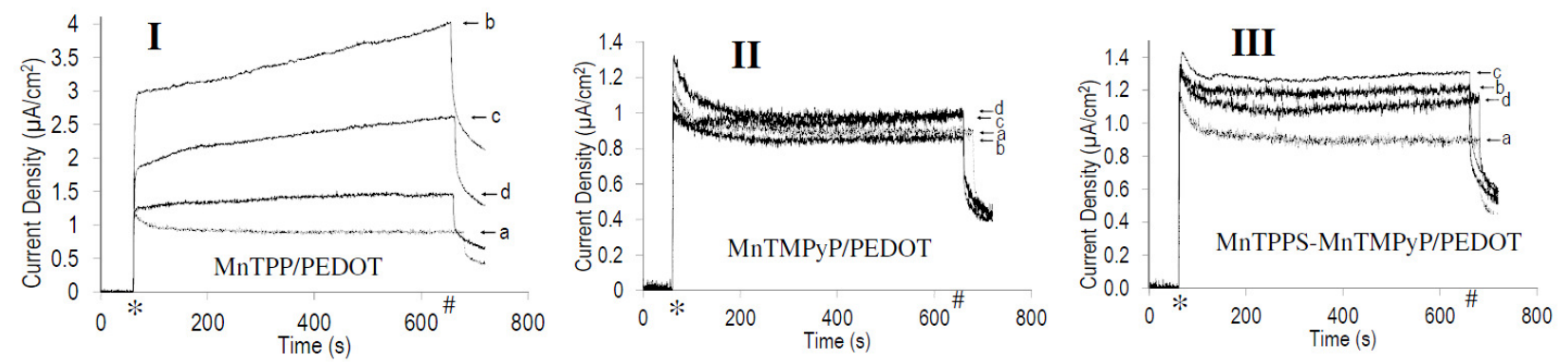

Figure 3. Chronoamperograms under light illumination at $0.7 \mathrm{~V}$ ( $\mathrm{vs} \mathrm{Ag} / \mathrm{AgCl}$ ) in $0.1 \mathrm{M} \mathrm{Na} 2 \mathrm{SO}_{4}$ solution of: (I) MnTPP/PEDOT, (II) MnTMPyP/PEDOT, and (III) MnTPPS+MnTMPyP/PEDOT, at loadings of the Mn porphyrin in PEDOT polymerisation solutions of: (a) $0 \mathrm{mg} / \mathrm{mL}$ (PEDOT only), (b) $1 \mathrm{mg} / \mathrm{mL}$, (c) $2 \mathrm{mg} / \mathrm{mL}$, and (d) $3 \mathrm{mg} / \mathrm{mL}$. (* = "light on"; \# = "light off")

\section{Photoelectrochemical testing of PEDOT and PEDOT/Mn porphyrins}

Each PEDOT film was tested with and without light illumination in $0.1 \mathrm{M} \mathrm{Na}_{2} \mathrm{SO}_{4}$. From these experiments baseline currents and photocurrents were determined at various applied voltages.

Figure 2 depicts linear sweep voltammograms in $0.1 \mathrm{M} \mathrm{Na}_{2} \mathrm{SO}_{4}$ solution, under light illumination and in the dark for PEDOT (control), MnTPP/PEDOT, MnTMPyP/PEDOT and MnTPPS+MnTMPyP/PEDOT. As can be seen, all of the films, including the control PEDOT displayed some level of light activation, although it was tiny in all cases except for MnTPP/PEDOT. The onset potentials of the films fell in the region about 0.40-0.55 V (vs. Ag/AgCl).

Figure 3 depicts chronoamperograms under light illumination of the films when poised at $0.7 \mathrm{~V}(\mathrm{vs} \mathrm{Ag} / \mathrm{AgCl})$ in 0.1 $\mathrm{M} \mathrm{Na}_{2} \mathrm{SO}_{4}$ solution. The curves (a) in all of the graphs in Figure 3 depict the photocurrent of the control PEDOT sample [17,23-24]. Curves (b)-(d) in Figure 3 depict the photocurrents of the Mn porphyrin PEDOT films with increasing loadings in the order: $1 \mathrm{mg} / \mathrm{ml}, 2 \mathrm{mg} / \mathrm{mL}$, and $3 \mathrm{mg} / \mathrm{mL}$, respectively. As can be seen, for MnTMPyP/PEDOT (II in Figure 3), and MnTPPS+MnTMPyP/PEDOT (III in Figure 3), the photocurrents at the 
different loading levels were either comparable to those of control PEDOT or not substantially different from each other. Clearly, the presence of the Mn porphyrins in the PEDOT had no significant effect on the observed photocurrents in these cases. The ion-pairing of MnTPPS and MnTMPyP prior to incorporation into PEDOT did not lead to increased photocurrents.

However, the MnTPP/PEDOT films (I in Figure 3) displayed photocurrents that were notably larger than that of the control PEDOT coating and of the other samples examined. The data showed the highest photocurrents observed, with a maximum of $4 \mu \mathrm{A} / \mathrm{cm}^{2}$ at $0.7 \mathrm{~V}$ (Figure 3(I)(b)).

Unexpectedly however, the MnTPP-PEDOT photocurrents scaled negatively with increasing concentration. That is, the lower the concentration of MnTPP in the sample, the higher the recorded photocurrent. Thus, for example, the sample containing a loading of $1 \mathrm{mg} / \mathrm{mL}$ yielded a photocurrent of $4 \mu \mathrm{A} / \mathrm{cm}^{2}$ (Figure 3(I)(b)), while $2 \mathrm{mg} / \mathrm{mL}$ produced only $2.5 \mu \mathrm{A} / \mathrm{cm}^{2}$ (Figure $3(\mathrm{I})(\mathrm{c})$ ) and $3 \mathrm{mg} / \mathrm{mL}$ generated $1.25 \mu \mathrm{A} / \mathrm{cm}^{2}$ (Figure 3(I)(d)).

This sequence is diametrically contradictory to previous studies, ${ }^{2}$ where increasing loadings of anionic MnTPPS in PEDOT led to larger photocurrents. Clearly, the photocurrent generated by MnTPP/PEDOT did not depend on the formation of face-to-face (H-) aggregates of MnTPP within the PEDOT. Instead, it must have been generated by another mechanism entirely.

\section{Gas generation under light illumination by MnTPP/PEDOT}

In order to further investigate, gases generated by MnTPP/PEDOT under light illumination were collected and tested. For this experiment, a cell comprising of two, sealed, gas-tight, half-cells, each separately maintained under flowing argon and each containing a quartz window for illumination with light, was used (Figure S2). The anode and cathode half-cells were connected to each other only via a gas-impermeable, ion-permeable Nafion 117 membrane that had cathode electrolyte on one side and anode electrolyte on the other.

Each half cell was filled with $0.1 \mathrm{M} \mathrm{Na}_{2} \mathrm{SO}_{4}$ solution. A $3 \mathrm{~cm}^{2} \mathrm{MnTPP} / \mathrm{PEDOT} / \mathrm{FTO}$ glass electrode was then fitted to the sealed anode half-cell which also included a $\mathrm{Ag} / \mathrm{AgCl}$ reference electrode. A Pt counter electrode was used in the sealed cathode half-cell.

Following overnight purging to remove all ambient $\mathrm{O}_{2}$ from the anode half cell (prior to illumination), the argon carrier gas passing through the anode half-cell was sampled, using a gas injection loop connected to a dedicated gas chromatograph, and shown to contain no gas other than Ar.

The MnTPP/PEDOT/FTO working electrode was thereafter maintained at a constant potential of $0.7 \mathrm{~V} \mathrm{vs.} \mathrm{Ag} / \mathrm{AgCl}$, whilst subjected through the anode quartz window, to an illumination of $>3$ sun provided by a Newport 65902 Xenon lamp. During illumination, bubbles could be seen to continuously form and release on the MnTPP/PEDOT/FTO electrode surface. After several hours, the carrier gas flowing through the cell was sampled. Three new gases were detected in the Ar carrier gas: oxygen, hydrogen, and a third gas, whose retention time matched that of carbon monoxide (Figure S3). This result was different to previous experiments involving PEDOT doped with anionic MnTPPS, which generated only oxygen under illumination.

In light of previous work involving VPP-PEDOT, with and without dopants, tested under essentially identical circumstances, the oxygen appeared likely to have come from the water [2]. However, we could not explain the origin of the hydrogen. The hydrogen did not appear to have originated at the counter-electrode since previous studies on comparable systems in the test cell and gas chromatograph employed had never before produced a hydrogen peak. The third gas, carbon monoxide, seemed to derive from a photolytic decomposition process unlike any we had observed before for this class of conducting film.

\section{Elemental Analysis of MnTPP/PEDOT}


An elemental analysis was conducted on the most photoactive of the MnTPP/PEDOT films ( $1 \mathrm{mg} / \mathrm{mL})$. A total of 24 replicate films were produced in order to prepare enough mass of composite $(\sim 10 \mathrm{mg})$ for elemental analysis. The films were carefully removed from the glass surface and combined. The elemental analysis was carried out using an EA 3000 instrument for $\mathrm{CNH}$ analysis, a Dionex for $\mathrm{S}$ and flame atomic absorption spectroscopy for Mn and Fe.

\begin{tabular}{ccc}
\hline Element & \% Expected & \% Found \\
\hline C & 46.57 & 43.63 \\
H & 2.56 & 3.41 \\
N & 0.54 & 0.58 \\
S & 18.46 & 18.11 \\
Mn & 0.53 & 0 \\
\hline
\end{tabular}

Table 1. Elemental analysis data for MnTPP/PEDOT

The results are presented in Table 1. As can be seen, based on the composition of the polymerization solution of 60:1 oxidant to MnTPP, the dried coating would have been expected to contain $46.57 \%$ carbon, $2.56 \%$ hydrogen, $0.54 \%$ nitrogen, $18.46 \%$ sulfur, and $0.53 \%$ manganese. Instead, the coating was found to contain $44.18 \%$ carbon, $3.20 \%$ hydrogen, $0.63 \%$ nitrogen, $18.06 \%$ sulfur, and $0.00 \%$ manganese. Those proportions corresponded to what would have been expected if the polymerization solution had contained a ratio of 54.6:1 monomer/oxidant to $(54.6 / 60 \times 100)=91 \%$ of the original TPP porphyrin, present in a metal-free form, not having a $\mathrm{Mn}$ ion bound to it.

The elemental analysis therefore yielded the startling fact that no Mn was present in the MnTPP/PEDOT film submitted for analysis. The Mn ion had somehow been ejected from the porphyrin and the film. The porphyrin remained intact within the PEDOT after the polymerization.

The loss of the Mn ion from the porphyrin must have occurred during or immediately after the PEDOT polymerization process. Given that $\mathrm{Mn}(\mathrm{III})$ is kinetically inert and therefore difficult to remove from the porphyrin, this could only have occurred if the Mn(III) was transformed or cycled through a Mn ion having a different oxidation level. Previous studies on the TPP complexes of Mn(II), Mn(III), Mn(IV) and Mn(V) have shown that only the Mn(II) variant is labile and capable of being removed from the porphyrin core. However, under normal conditions, Mn(II)TPP immediately and irreversibly forms the Mn(III)TPP when exposed to air oxygen [15,25,26].

In order to investigate what had happened, UV-Visible spectroscopic analysis was undertaken on the Mn porphyrin films, including the MnTPP/PEDOT film.

\section{UV-visible spectroscopy of Mn porphyrin / PEDOT during vapour phase polymerization}

Solutions of the PEDOT / Mn porphyrin species in $80 \%$ ethanol/water were prepared and spin-coated onto glass slides. Their UV-Vis absorbance profile was then studied.

The UV-Vis spectrum of PEDOT featured its well-known absorption tail into the infrared (Figure S4). However, when loaded with Mn porphyrins, the most prominent peak became the porphyrin Soret band. These peaks were observed at $477 \mathrm{~nm}$ for PEDOT containing MnTPPS, MnTMPyP or MnTPPS+ MnTMPyP, and at $485 \mathrm{~nm}$ for MnTPP (Figure 4). The Soret band for the ion-paired mixture of MnTPPS+MnTMPyP was somewhat broadened.

In order to investigate possible changes to the porphyrin structure induced by the Fe-pTS oxidant used in the vapour phase polymerization process, solutions of the Mn porphyrins in $80 \%$ ethanol/water, including the VPP oxidant and pyridine, were prepared and spin-coated onto glass slides. Under these conditions, the Soret bands were observed at $473.5 \mathrm{~nm}$ for MnTPP, $469.5 \mathrm{~nm}$ for MnTMPyP, 471.5 for MnTPPS and 470.5 nm for MnTPPS+MnTMPyP (Figure 5). A broad, intense peak was observed for Fe-pTS and pyridine starting at $450 \mathrm{~nm}$ and extending into the UV region (Figure 5(a)). 


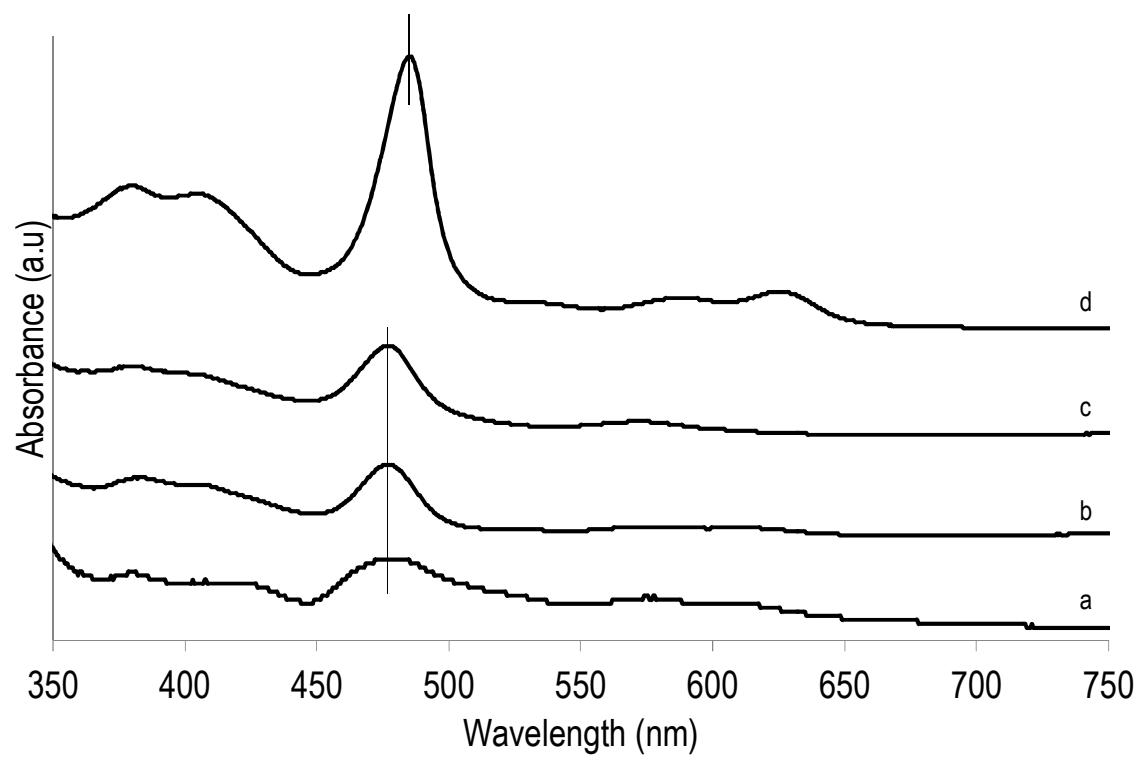

Figure 4. Superimposed UV-Vis spectra of porphyrin species deposited on glass in the same fashion as for VPP, but without the oxidant present: (a) MnTPPS+MnTMPyP, (b) MnTPPS, (c) MnTMPyP, (d) MnTPP. The Soret band peaks are marked with a vertical line.

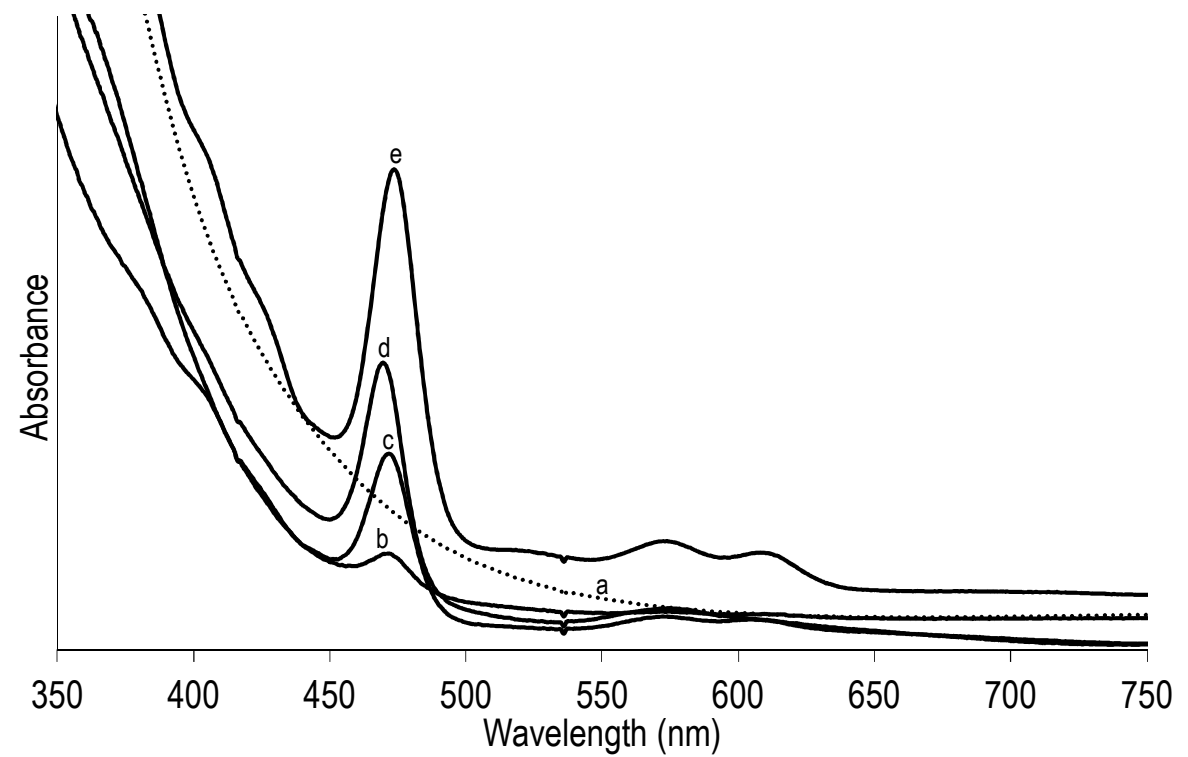

Figure 5. Superimposed UV-Vis spectra of porphyrin species deposited on glass in the same fashion as the vapour phase polymerization procedure, including the oxidant but before polymerisation. (a) No Mn porphyrin and (b) MnTPPS+MnTMPyP, (c) MnTPPS, (d) MnTMPyP, (e) MnTPP

The small shift in the Soret Band wavelengths of ca. 6-10 nm for each porphyrin compared to the films without oxidant, was consistent for all of the spectra, covering both the Soret and Q-bands. The Mn porphyrins therefore clearly did not react with the Fe-pTS oxidant present during vapour phase polymerization. The demetallation that was observed for the MnTPP/PEDOT films could, consequently, not have been due to a reaction with the Fe-pTS oxidant.

\section{UV-visible spectroscopy of porphyrin leached from Mn/ PEDOT/ITO glass}


In light of the elemental analysis results indicating an absence of $\mathrm{Mn}$ in the samples, the porphyrin in the MnTPP samples was leached out of the films and analyzed separately from the film itself. MnTPP is highly soluble in ethanol, which was why the MnTPP/PEDOT films were washed with water after vapour phase polymerization rather than with ethanol.

For this experiment, a small amount of ethanol was added drop-wise onto the top of a MnTPP/PEDOT film (1 $\mathrm{mg} / \mathrm{mL}$ ) and the run-off captured in a sample vial. The ethanol turned a green colour upon contacting the film, indicating ready leaching of the porphyrin from the film. The ethanolic leachate was then analyzed by UV-Vis spectroscopy and compared to the UV-visible spectrum for MnTPP and free base TPP.

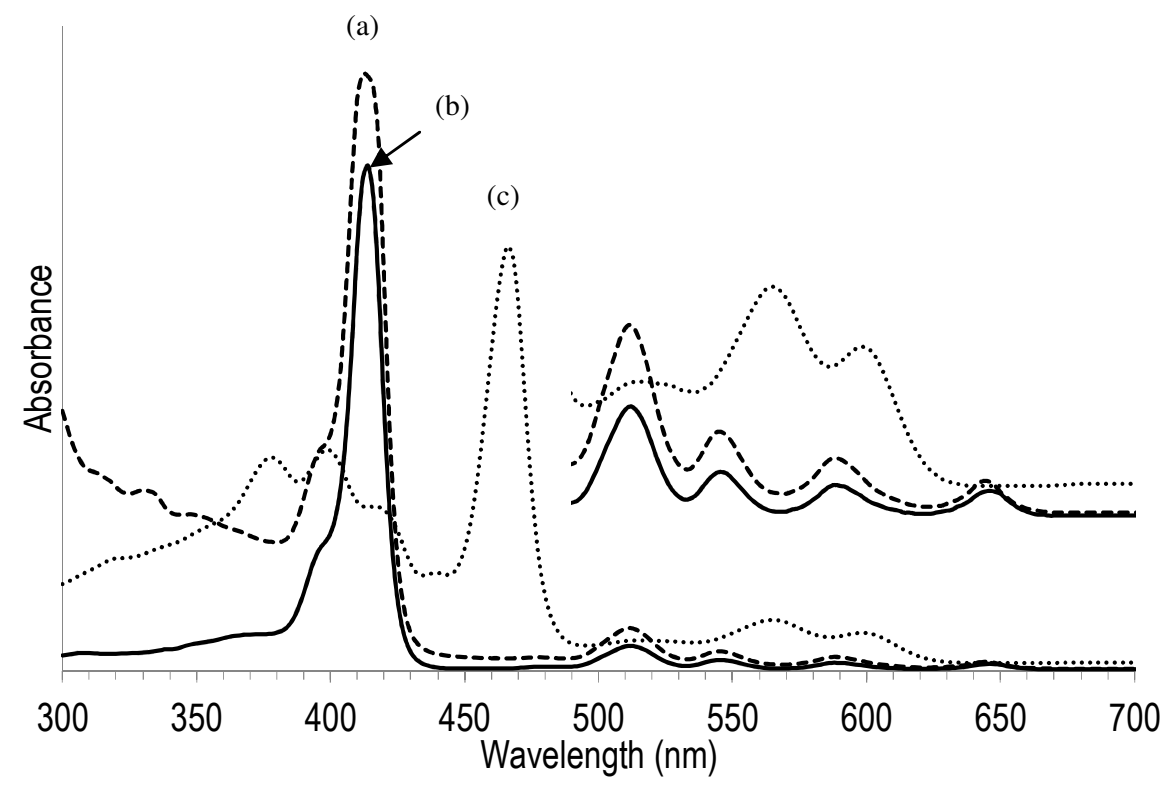

Figure 6. UV-Vis spectra of porphyrins in ethanol: (a) porphyrin leached from MnTPP/PEDOT film by washing with ethanol, (b) free base TPP, (c) MnTPP.

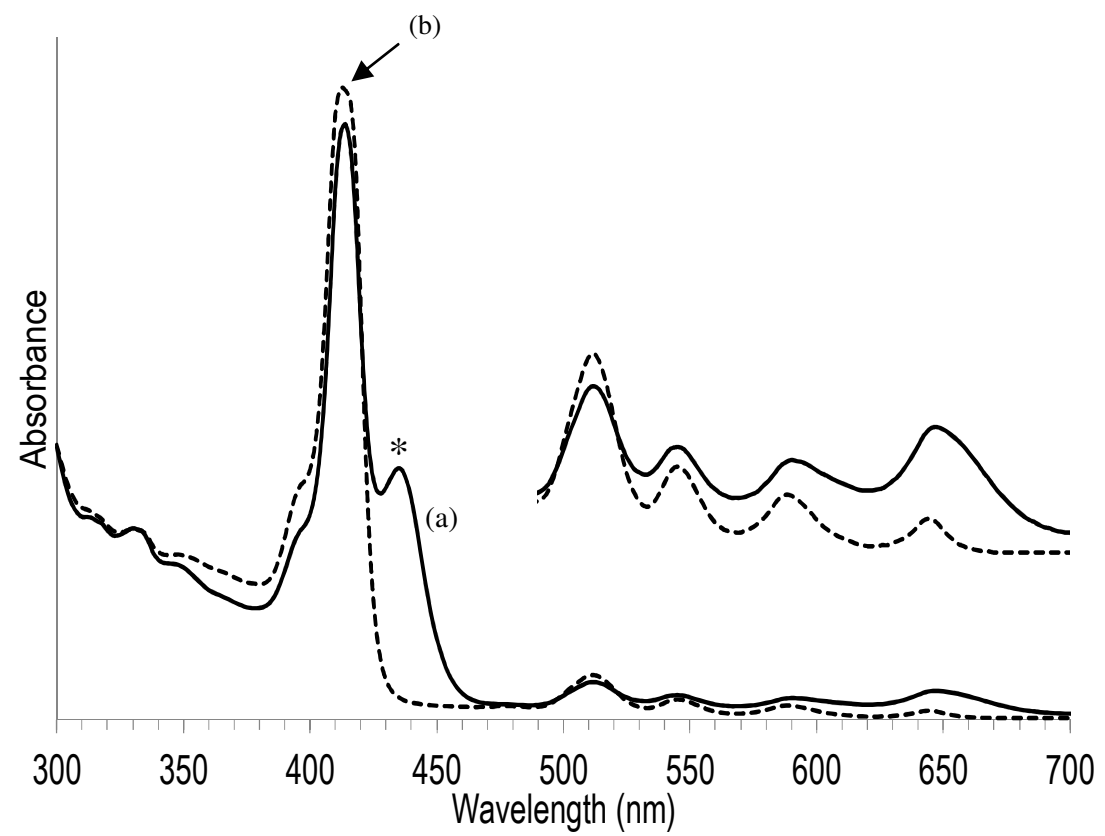

Figure 7. UV-Vis spectra of porphyrins in ethanol: (a) porphyrin leached from MnTPP/PEDOT film that had not been exposed to water showing $\left(^{*}\right)$ a new peak at $436 \mathrm{~nm}$, (b) free base TPP. 
As can be seen in Figure 6, the Soret band of MnTPP in ethanol falls at $466 \mathrm{~nm}$, while that of the free base TPP is observed at $415 \mathrm{~nm}$. The spectrum of the porphyrin rinsed out of MnTPP/PEDOT films using ethanol was identical to that of free TPP, including the Q-bands in the 490-660 $\mathrm{nm}$ region. The ethanol rinse was also analyzed by MALDI and shown to produce a major peak at $613 \mathrm{~m} / \mathrm{z}$, which corresponded to the free base TPP. These results confirmed the elemental analysis data that there was no $\mathrm{Mn}$ in the film. One possible inference was that the Mn must have been lost from the film during the step of washing with water immediately after vapour phase polymerization.

A second sample of MnTPP/PEDOT was prepared in the same way, without the final step of washing the MnTPP/PEDOT in water as is normally part of the fabrication process. This was done in order to examine the state of the porphyrin inside MnTPP/PEDOT without it coming into contact with water at any stage. The porphyrin in that film was thereafter leached with ethanol and analyzed using UV-Vis spectroscopy.

The UV-Vis spectrum of the porphyrin leached out of this sample using ethanol was identical to that of the previous MnTPP/PEDOT sample, except for the presence of an extra peak at $436 \mathrm{~nm}$ (Figure 7). Neither spectrum indicated that the porphyrin in the film was in the original Mn(III)TPP form; it had clearly already changed within the polymer matrix, even before being washed with water and during the vapour phase polymerization process itself.

The absorbance peak at $415 \mathrm{~nm}$ for the porphyrin leached out of MnTPP/PEDOT was unequivocally that of the free base porphyrin TPP, indicating that the porphyrin became demetallated during the polymerization process.

To investigate the second peak at $436 \mathrm{~nm}$, further experimentation was necessary. One possible candidate for the peak at $436 \mathrm{~nm}$ was the Soret band of Mn(II)TPP [15]. As depicted in Table 2, the Soret band of Mn(II) porphyrins typically fall at 430-440 $\mathrm{nm}$. The Q-bands of this particular species may also be masked by the more intense absorbance displayed by the free base TPP.

\begin{tabular}{ccccc}
\hline & \multicolumn{3}{c}{ Wavelength (nm) } & \\
Porphyrin & \multicolumn{3}{c}{ Mn Oxidation state } & Ref. \\
& II & III & IV & \\
\hline MnTPPS (in water) & 436 & 469 & 424 & 10,25 \\
MnTMPyP (in water) & 441 & 463 & 422 & 10,25 \\
MnTPP (in water emulsion) & 432 & 468 & 418 & 28 \\
MnTPP (in $\mathrm{CH}_{2} \mathrm{Cl}_{2}$ ) & & 478 & 425 & 28
\end{tabular}

Table 2. Soret band wavelengths of Mn porphyrins in different oxidation states.

As noted earlier, demetallation of Mn(II)TPP has been reported in the scientific literature, in acidic aqueous solution [15,25-27]. This suggested that the Mn(III) porphyrin had been reduced to the $\mathrm{Mn}(\mathrm{II})$ analogue during the formation of the PEDOT conducting polymer, with the metal ion then expelled by interaction with an acidic species. Such a reaction would be highly unusual as reduction of $\mathrm{Mn}(\mathrm{III})$ porphyrin normally requires a strong reducing agent and a complete absence of air oxygen. Given the abundant presence of the strongly oxidizing Fe-pTS in the polymerization mixture and the air atmosphere during the vapour phase polymerization, one would expect the presence of a Mn(III)porphyrin and not a reduced $\mathrm{Mn}(\mathrm{II})$ porphyrin.

\section{UV-visible spectrum of Mn(II)TPP and subsequent de-metallation}

Mn(III)TPP in ethanol was reduced to Mn(II)TPP using sodium borohydride under inert atmosphere and subsequently demetallated following the method described in the experimental section. The porphyrin species at each step along this pathway were characterized by UV-Vis spectroscopy. 
As can be seen in Figure 8, the Soret band in ethanol of Mn(III)TPP at $466 \mathrm{~nm}$ (Figure 8(a)) shifted to $432 \mathrm{~nm}$ for Mn(II)TPP under inert atmosphere (Figure 8(b)) [15]. Exposure of the Mn(II)TPP solution to air resulted in immediate regeneration of $\mathrm{Mn}(\mathrm{III}) \mathrm{TPP}$. When degassed deionized water was added to the Mn(II)TPP solution under inert atmosphere, the Soret Band at $432 \mathrm{~nm}$ split into two bands at $420 \mathrm{~nm}$ (which was close to that of free TPP at $415 \mathrm{~nm}$ ) and $466 \mathrm{~nm}$ (which was characteristic of Mn(III)TPP) (Figure 8(c)). The characteristic Q-bands of free TPP were also observed at $514 \mathrm{~nm}, 550 \mathrm{~nm}, 590 \mathrm{~nm}$ and $645 \mathrm{~nm}$.

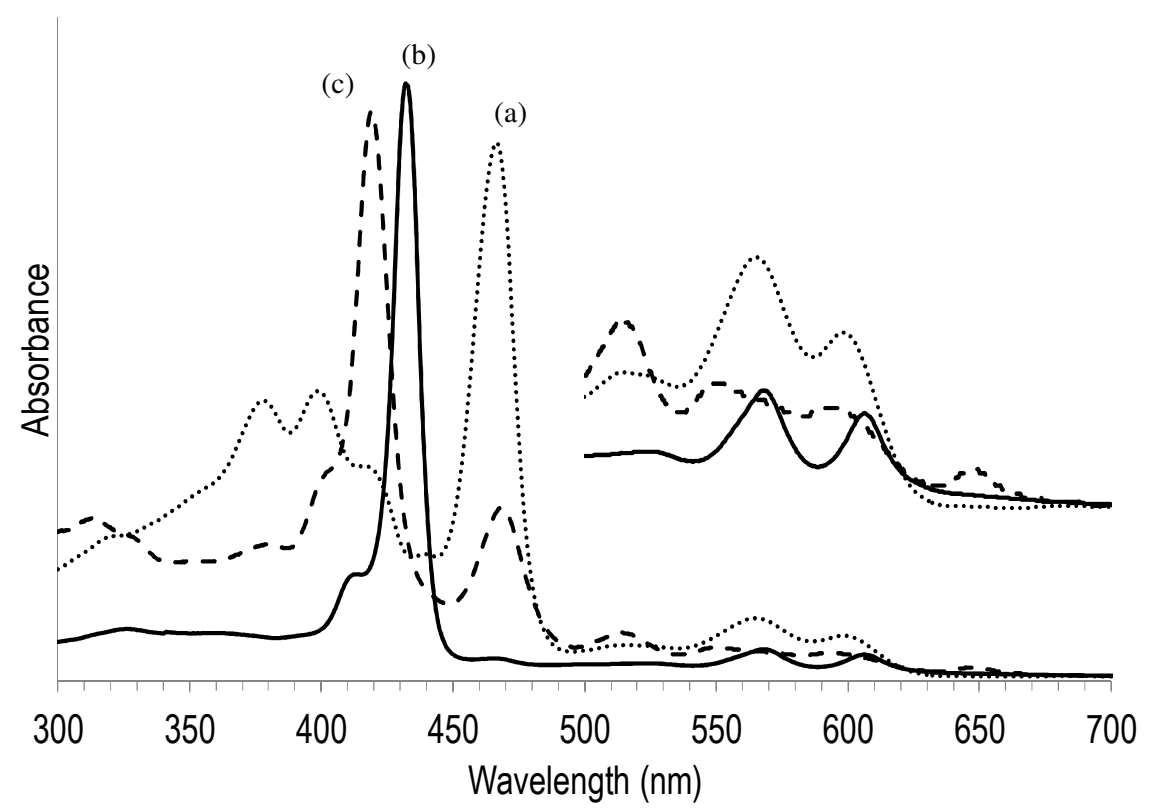

Figure 8. UV-Vis spectra of porphyrins in ethanol: (a) Mn(III)TPP, (b) Mn(II)TPP (under inert atmosphere), (c) Mn(II)TPP after the addition of water under inert atmosphere.

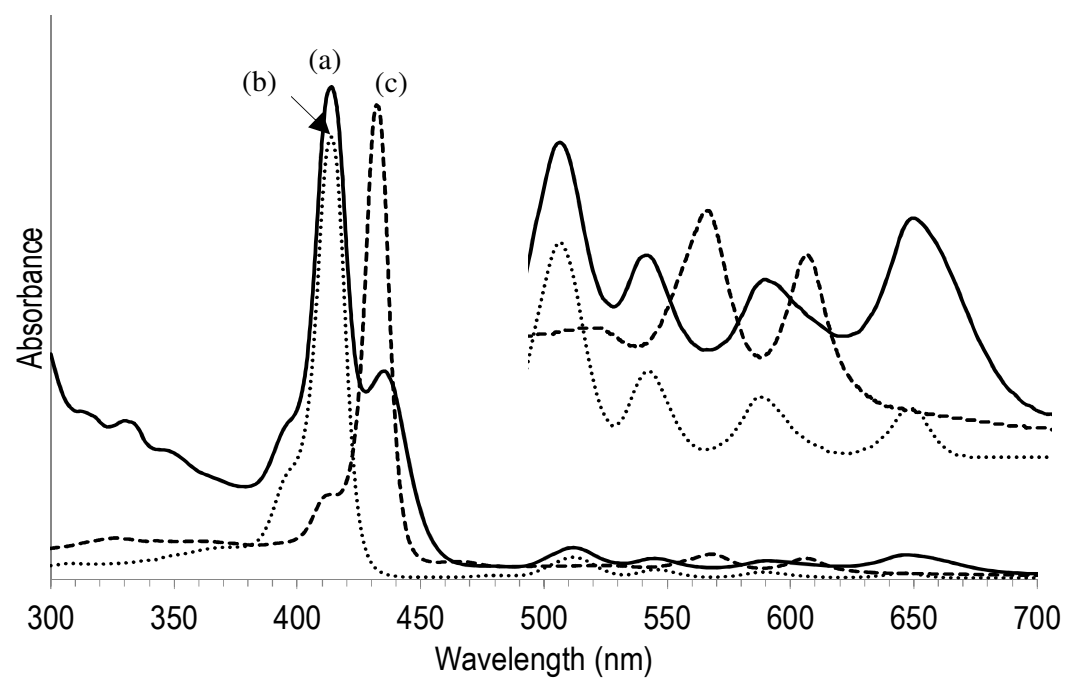

Figure 9. UV-Vis spectra of: (a) ethanol wash leached from MnTPP/PEDOT that had not been treated with water during its preparation, (b) free base TPP, (c) Mn(II)TPP 
These spectra were compared to those of an ethanol wash leached from MnTPP/PEDOT film samples that had not been treated with water at any stage (Figure 9). The absorbance bands at $415 \mathrm{~nm}$ and $432 \mathrm{~nm}$ of the ethanol leachate (Figure 9(a)) could be attributed to the Soret bands of free base TPP (Figure 9(b)) and Mn(II)TPP (Figure 9(c)). However, the Q-bands of the leached sample did not display any similarity to that of Mn(II)TPP, instead mirroring those of TPP. Mn(II)TPP displayed two distinct absorbance peaks at $567 \mathrm{~nm}$ and $606 \mathrm{~nm}$, while the leachate had four absorbance peaks at $514 \mathrm{~nm}, 550 \mathrm{~nm}, 590 \mathrm{~nm}$ and $645 \mathrm{~nm}$, which corresponded to those of free TPP. This indicated that the second species in the unwashed MnTPP/PEDOT film that absorbed at $432 \mathrm{~nm}$, was not Mn(II)TPP.

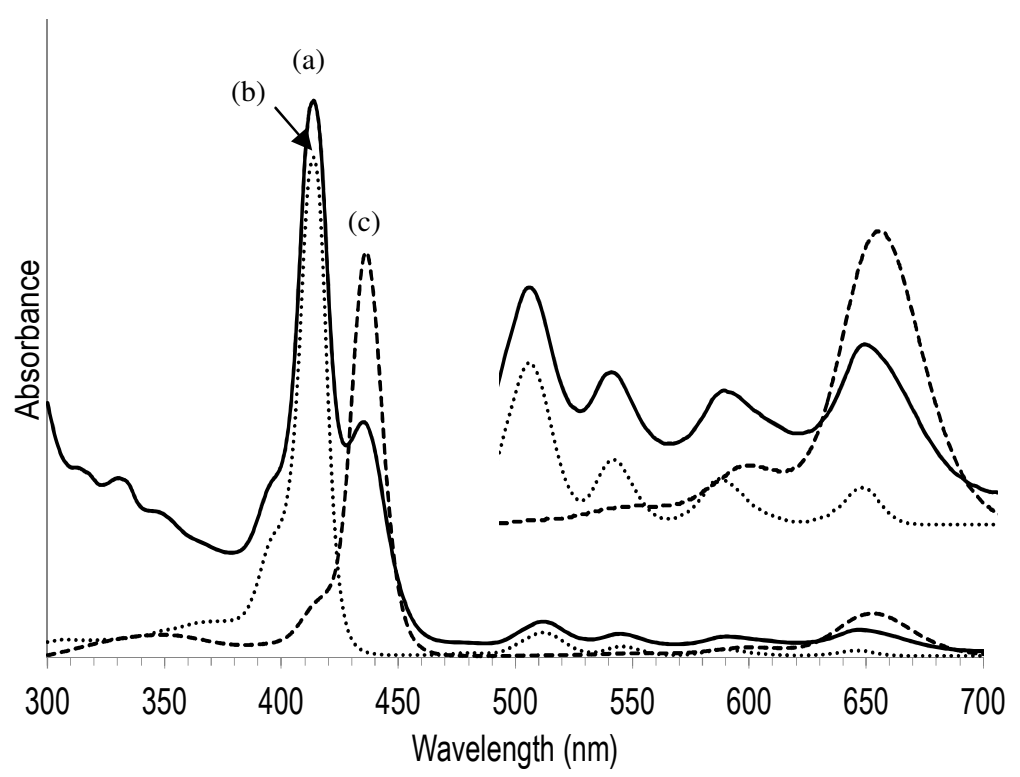

Figure 10. UV-Vis spectra in ethanol of: (a) porphyrin leached from MnTPP/PEDOT that had not been treated with water, (b) free base TPP, (c) protonated $\mathrm{H}_{4} \mathrm{TPP}^{2+}$.

\section{UV-visible spectroscopy of protonated TPP}

One more variant of the TPP porphyrin was explored by UV-Vis analysis, namely, that of the protonated free base, $\mathrm{H}_{4} \mathrm{TPP}^{2+}$. In a similar experiment, free base TPP was protonated as described in the experimental section and compared to that of the above ethanol leachate (Figure 10).

The UV-Vis spectrum of protonated $\mathrm{H}_{4} \mathrm{TPP}^{2+}$ (Figure 10(c)) displayed a notable overlap with the spectrum of the leachate (Figure 10(a)). Indeed, the Soret Band position of the protonated $\mathrm{H}_{4} \mathrm{TPP}^{2+}$ species corresponded well with the absorbance of the leachate at $436 \mathrm{~nm}$ [9]. Moreover, the protonated porphyrin featured two instead of four Q-band peaks at $600 \mathrm{~nm}$ and $652 \mathrm{~nm}$. This was very close to two of the four TPP Q-band peaks at 588 and $646 \mathrm{~nm}$. The Qbands in the leachate spectrum additionally exhibited an unusually intense peak at $646 \mathrm{~nm}$; more intense than the corresponding peak in a solution spectrum of free base TPP alone. The leachate spectrum was thereby shown to be a composite spectrum of free TPP mixed with protonated $\mathrm{H}_{4} \mathrm{TPP}^{2+}$, indicating that the porphyrin leached out of the MnTPP/PEDOT was a mixture of free TPP and protonated $\mathrm{H}_{4} \mathrm{TPP}^{2+}$.

The common route for demetallation of Mn(III)TPP identified in the scientific literature involves reduction of $\mathrm{Mn}(\mathrm{III})$ to $\mathrm{Mn}$ (II) and subsequent protonation of the core, leading to loss of the metal ion from the porphyrin [15,2527]. Vapour phase polymerization of PEDOT produces acid groups [16] that could be sufficient to protonate free base TPP, which has a $\mathrm{pK}_{\mathrm{a}}$ of 3.9 [28]. However it was unclear how the reduction to $\mathrm{Mn}$ (II) could have occurred in an environment containing an excess of oxidizing agent. 


\section{Effect of concentration of porphyrin in MnTPP/PEDOT}

To test the unusual relationship between porphyrin concentration and photocurrent, MnTPP/PEDOT samples were prepared with a higher loading of the porphyrin. Films containing $10 \mathrm{mg} / \mathrm{mL}(14.18 \mathrm{mM})$ and $23 \mathrm{mg} / \mathrm{mL}(32.27 \mathrm{mM})$ of MnTPP were prepared. These were assessed by chronamperometry with and without light illumination as had been done with prior samples. The films were, additionally, analyzed by UV-Vis and compared to previous spectra, with the porphyrins contained in them washed out of the film using ethanol.

\begin{tabular}{cc}
\hline MnTPP loading in PEDOT & Photocurrent Density $\left(\mu \mathrm{A} / \mathrm{cm}^{2}\right)$ \\
\hline $1 \mathrm{mg} / \mathrm{mL}$ & 4.01 \\
$2 \mathrm{mg} / \mathrm{mL}$ & 2.62 \\
$3 \mathrm{mg} / \mathrm{mL}$ & 1.47 \\
$10 \mathrm{mg} / \mathrm{mL}$ & 1.52 \\
$23 \mathrm{mg} / \mathrm{mL}$ & 0.40
\end{tabular}

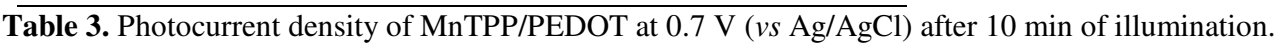

Table 3 summarizes the photocurrents obtained for all of the MnTPP/PEDOT films prepared, including those with loading levels of $10 \mathrm{mg} / \mathrm{mL}$ and $23 \mathrm{mg} / \mathrm{mL}$. As can be seen, the photocurrent densities displayed for MnTPP/PEDOT at $10 \mathrm{mg} / \mathrm{mL}$ and $23 \mathrm{mg} / \mathrm{mL}$ loading levels demonstrated significantly lower photocurrents compared to films with lower porphyrin loadings (except in the case of $1 \mathrm{mg} / \mathrm{mL}$ ).

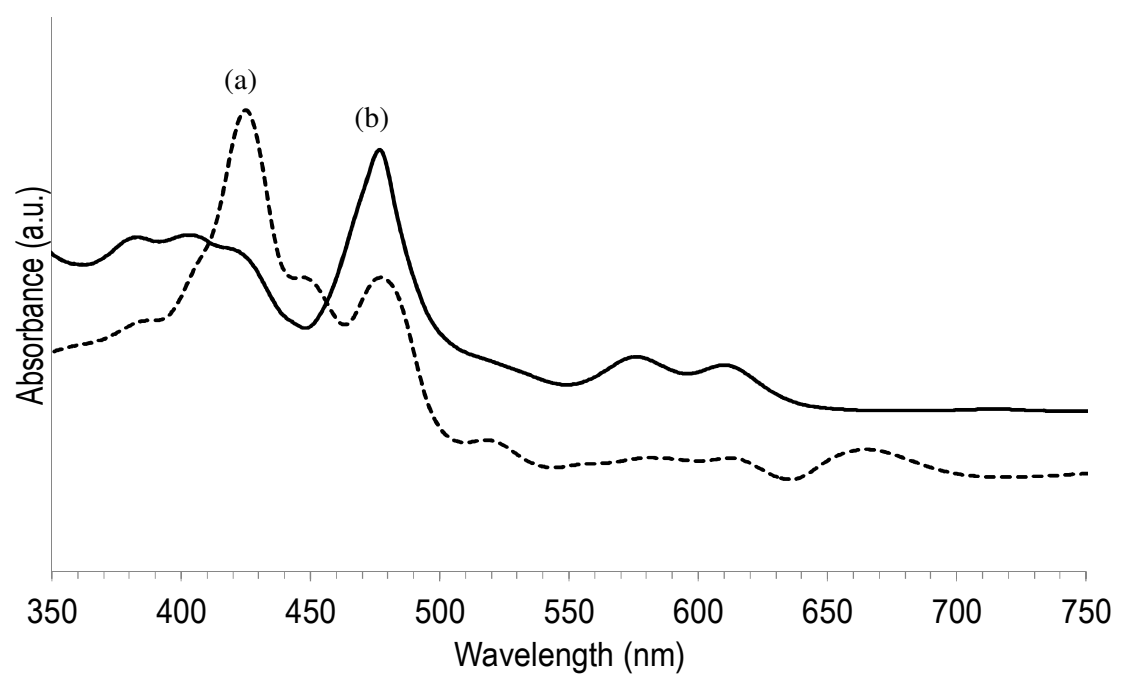

Figure 11. UV-Vis spectra of MnTPP/PEDOT with loadings of MnTPP in PEDOT polymerisation solution of: (a) $10 \mathrm{mg} / \mathrm{mL}$ and (b) $23 \mathrm{mg} / \mathrm{mL}$.

The UV-Vis spectra of the two new films with higher concentrations of porphyrin, displayed an interesting phenomenon (Figure 11). The $10 \mathrm{mg} / \mathrm{mL}$ MnTPP/PEDOT sample exhibited the familiar absorbance peaks at $425 \mathrm{~nm}$ and $447 \mathrm{~nm}$, corresponding to free base TPP and $\mathrm{H}_{4} \mathrm{TPP}^{2+}$, as well as a third absorbance peak at $477 \mathrm{~nm}$. The $477 \mathrm{~nm}$ peak corresponded to the Soret band of Mn(III)TPP, indicating that at least some of the Mn porphyrin remained in its initial metalloporphyrin state and had not undergone demetallation. The spectrum of the $23 \mathrm{mg} / \mathrm{mL}$ MnTPP/PEDOT was dramatically different, closely resembling a typical Mn(III)TPP solution spectrum; the Soret Band at $477 \mathrm{~nm}$ was present as the dominant peak and for the first time the Q-bands at 576 and $610 \mathrm{~nm}$ were clearly discernible. 
UV-visible analysis of ethanol rinses of the $10 \mathrm{mg} / \mathrm{mL}$ and $23 \mathrm{mg} / \mathrm{mL}$ MnTPP/PEDOT, compared to that of 1.5 $\mathrm{mg} / \mathrm{mL}$ MnTPP/PEDOT (Figure 12), showed a gradual transition from predominantly $\mathrm{H}_{2} \mathrm{TPP}$ in the $1.5 \mathrm{mg} / \mathrm{mL}$ film (Figure 12(a)) to a mixed population of $\mathrm{H}_{2}$ TPP and Mn(III)TPP in the $10 \mathrm{mg} / \mathrm{mL}$ film (Figure 12(b)), and then to solely Mn(III)TPP in the $23 \mathrm{mg} / \mathrm{mL}$ film (Figure 12(c)). It was thereby clear that the photocurrent activity of the composite MnTPP/PEDOT film was due to the free base form of TPP and, in fact, diminished with higher presence of Mn(III)TPP in the film.

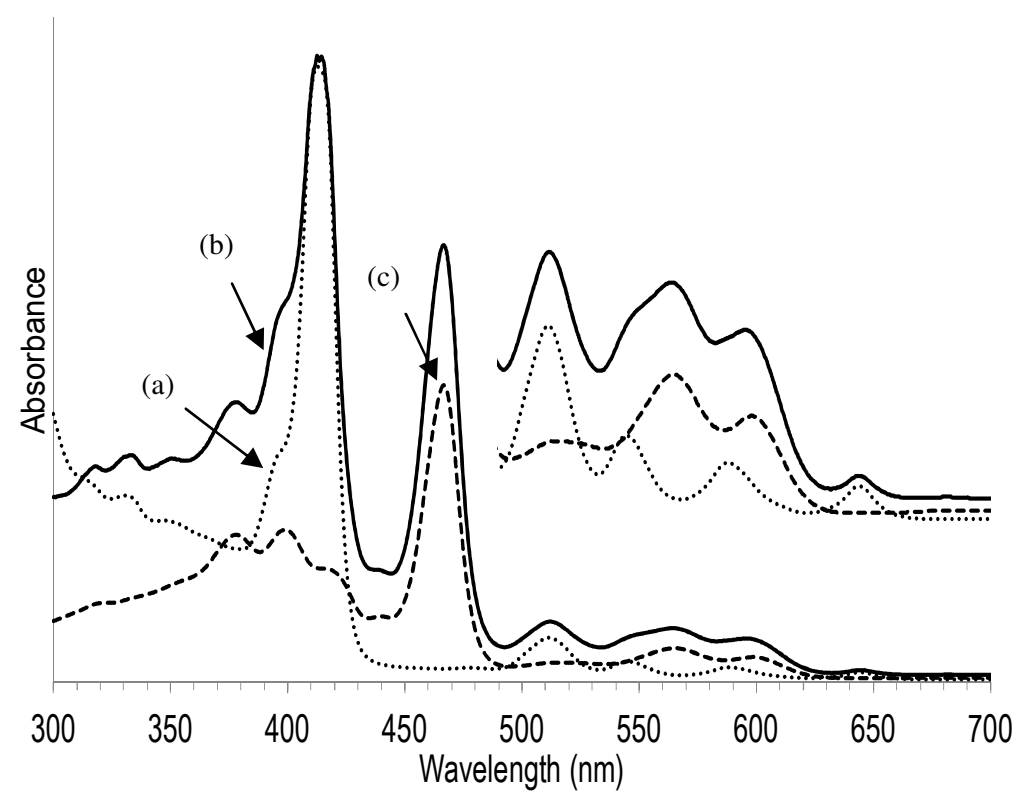

Figure 12. UV-Vis spectra of ethanol leachate from MnTPP/PEDOT having loadings of MnTPP in PEDOT polymerisation solution of: (a) $1.5 \mathrm{mg} / \mathrm{mL}$, (b) $10 \mathrm{mg} / \mathrm{mL}$ and (c) $23 \mathrm{mg} / \mathrm{mL}$

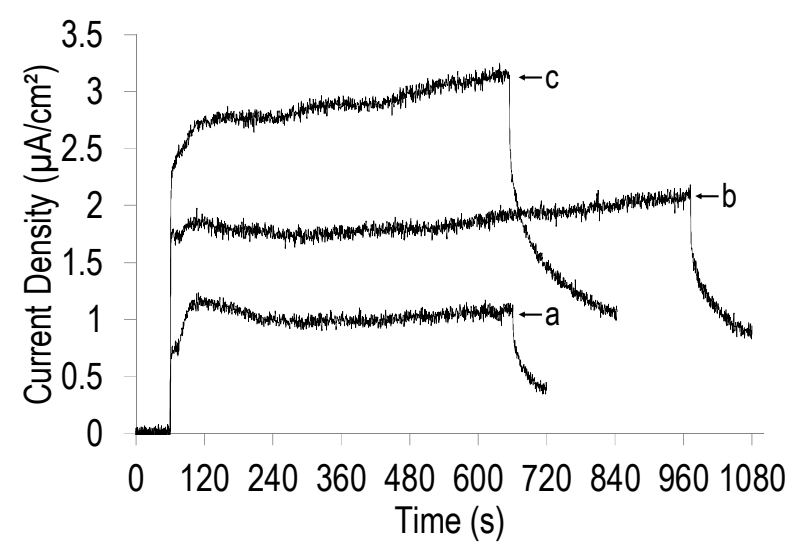

Figure 13. Chronoamperometry of TPP/PEDOT under light illumination at (a) $0.6 \mathrm{~V}$, (b) $0.65 \mathrm{~V}$, (c) $0.7 \mathrm{~V}$ (all $v s \mathrm{Ag} / \mathrm{AgCl}$ )

\section{Analysis of the free base porphyrin/PEDOT composite, TPP/PEDOT}

Given the results of the above analysis, it was prudent to test a film containing free TPP for its photocurrent. Therefore, a TPP/PEDOT film was prepared by vapour phase polymerization following the same procedure as employed in the earlier films. This time, TPP $(1.5 \mathrm{mg} / \mathrm{ml})$ was used in the porphyrin/oxidant mixture.

The resulting TPP/PEDOT film was then tested electrochemically under light illumination, as well as by UV-Vis spectroscopy. The film was tested for photocurrent activity under the same conditions as had been previously applied to 
MnTPP/PEDOT and it returned very similar results. The chronoamperogram under light illumination produced a photocurrent at $0.7 \mathrm{~V}$ vs $\mathrm{Ag} / \mathrm{AgCl}$ of $3.14 \mu \mathrm{A} / \mathrm{cm}^{2}$ compared to $2.62 \mu \mathrm{A} / \mathrm{cm}^{2}$ for MnTPP/PEDOT (Figure 13).

UV-Vis absorbance of the TPP/PEDOT film revealed a spectrum similar to that of an earlier prepared $2 \mathrm{mg} / \mathrm{mL}$ MnTPP/PEDOT (Figure 14). Both displayed the characteristic absorbance peaks at $424 \mathrm{~nm}$ and $447 \mathrm{~nm}$, corresponding to the Soret Bands of the free base TPP and $\mathrm{H}_{4} \mathrm{TPP}^{2+}$. They also both showed the peak having amplified intensity at ca. $660 \mathrm{~nm}$ that is characteristic of $\mathrm{H}_{4} \mathrm{TPP}^{2+}$. From this comparison, it could be concluded that, during vapour phase polymerization of the PEDOT films containing low loadings of MnTPP, the Mn ion was ejected from the core of the porphyrin and the film converted to TPP/PEDOT. This did not occur with MnTPP films having higher loading levels, of $23 \mathrm{mg} / \mathrm{mL}$ MnTPP or above.

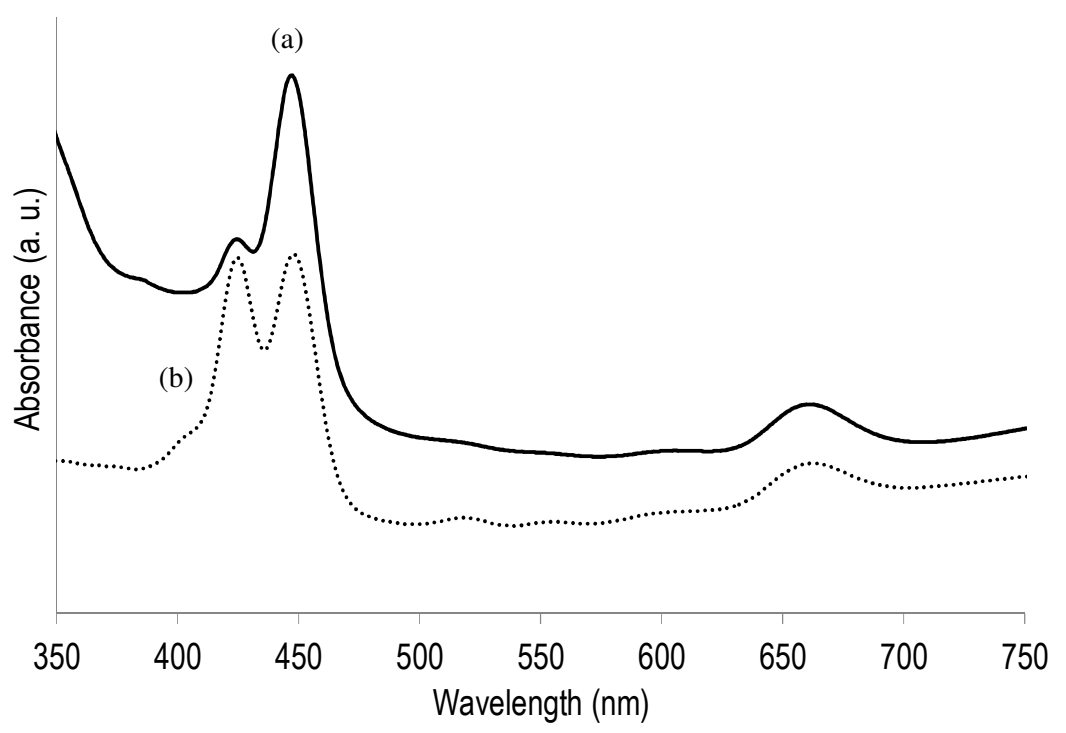

Figure 14. UV-Vis spectra of (a) $1.5 \mathrm{mg} / \mathrm{mL}$ TPP/PEDOT and (b) $2 \mathrm{mg} / \mathrm{mL}$ MnTPP/PEDOT.

\section{CONCLUSIONS AND SUMMARY}

In previous work [2], changes in the Soret Band of Mn porphyrins embedded in PEDOT were hypothesized to be due to the proximity and face-to-face orientation of individual molecules to one another, as was observed in cofacial porphyrin systems in the past [3-5,29-33]. More significant shifts in wavelength of the Soret Band peaks were thought of in terms of changes in the oxidation state of the Mn ion (Table 2).

In the case of low loadings of MnTPP however, the opposite was observed, namely, that the changes were due to reduction of the $\mathrm{Mn}$ (III) ion to the $\mathrm{Mn}$ (II) state with subsequent demetallation of the porphyrin. This seems paradoxical given the highly oxidative conditions in the polymerization. Indeed, tests that were conducted to assess the interaction between the MnTPP and the chemical oxidant species, Fe-pTS hexahydrate, showed no discernible chemical reaction between the species, such as oxidation or protonation of the porphyrin.

Studies, however, clearly point to the porphyrin inside the polymer matrix being in its demetallated state when present in low loadings, generating the typical TPP Soret Band peak at $414 \mathrm{~nm}$ in solution and $425 \mathrm{~nm}$ inside the film. From the UV-Vis data it is apparent that the Soret band peak at $447 \mathrm{~nm}$ arises from the acidified TPP in the film meaning that at the point of polymerization, the MnTPP was partly converted to $\mathrm{H}_{4} \mathrm{TPP}^{2+}$.

Subsequent tests of polymer samples containing free base TPP showed an identical absorbance profile to that of samples containing MnTPP, indicating, unequivocally, that the porphyrin in the film was in its free, demetallated state. 
One possible explanation for the change in the oxidation state of the Mn ion exclusively in low loadings, is photoreduction of the starting $\mathrm{Mn}$ (III) to $\mathrm{Mn}$ (II) by ambient light. Reduction of Mn(III) to Mn(II) when illuminated by light, is a well-documented phenomenon and has previously been noted to be associated with demetallation [34]. In the above systems, this process was evidenced by visible light absorbance analysis of the Soret Band, which shifted from $466 \mathrm{~nm}$ in Mn(III)TPP to $432 \mathrm{~nm}$ in Mn(II)TPP [15].

It should be noted that such a photoreduction was not observed during the preparation of solutions for UV-Vis analysis with Mn(III)TPP alone. These studies involved a carefully degassed solvent [12,27,35], as was also required when the porphyrin was reduced in solution using sodium borohydride. Without an inert atmosphere, the porphyrin would quickly oxidize back to its $\mathrm{Mn}(\mathrm{III})$ ion upon even minute exposure to air oxygen.

It seems likely that the PEDOT matrix may have facilitated enhanced photoreduction of the incorporated MnTPP by ambient light during or immediately after vapour phase polymerization. This process seemed to go to completion very rapidly without a significant sensitivity to the presence of air oxygen. All of this, however, took place in the presence of a strong oxidising agent within the polymerization solution, Fe-pTS, which clearly did not halt or hinder the photoreduction process. Perhaps most remarkably, the photoreduction appeared to have occurred only at loadings below ca. $23 \mathrm{mg} / \mathrm{mL}$ MnTPP. It may be that at higher loadings, the process was limited by the optical transparency of the PEDOT film.

The simultaneous formation of oxygen and hydrogen when low-loaded MnTPP/PEDOT films were subjected to light illumination at constant potential of $0.7 \mathrm{~V}(v s \mathrm{Ag} / \mathrm{AgCl})$ and the inverse relationship between loading and photocurrent can now also be explained. Free base TPP is known to undergo ready photolytic degradation when illuminated with light at its Soret and Q-band wavelengths [36]. It appears that the free base TPP generated in the PEDOT at low loadings underwent photoelectrolytic degradation, releasing hydrogen and oxygen, as well as carbon monoxide, and creating a "photocurrent" that increased as the amount of free base TPP in the coating was increased. Thus, at low loading levels, more free base TPP was present, yielding higher apparent photocurrents.

In summary: whereas PEDOT incorporating anionic MnTPPS is an active and selective photocatalyst of water oxidation, PEDOT containing the cationic Mn porphyrins tested in this work was catalytically inactive. Instead, incorporation of cationic MnTPP in PEDOT led to dematallation of the MnTPP, presumably through the action of light irradiation. The extent of demetallation increased as the loading level of the MnTPP in the PEDOT was decreased (below $23 \mathrm{mg} / \mathrm{mL}$ ). This observed dependence on the loading level may originate in, and be limited by the optical transparency of the PEDOT film.

\section{Acknowledgements}

DB acknowledges financial support during his $\mathrm{PhD}$ by the Australian Research Council.

\section{REFERENCES}

1. J. Chen, P. Wagner, L. Tong, G.G. Wallace, D.L. Officer, and G.F. Swiegers, Angew. Chem. Int. Ed. 2012, 51, 1907-1910.

2. J. Chen, P. Wagner, L. Tong, D. Boskovic, W. Zhang, D. Officer, G.G. Wallace, and G.F. Swiegers, Chem. Sci. 2013, 4, 2797-2803.

3. Y. Naruta, and M.-A. Sasayama, J. Chem. Soc., Chem. Commun. 1994, 2667-2668.

4. Y. Naruta, M.-A. Sasayama, and T. Sasaki, Angew. Chem. Int. Ed. Engl. 1994, 33, 1839-1841. 
5. Y. Shimazaki, T. Nagano, H. Takesue, B.-H. Ye, F. Tani, and Y. Naruta, Angew. Chem. Int. Ed. 2004, 43, 98100.

6. A. D. Adler, F.R. Longo, J.D. Finarelli, J. Goldmacher, J. Assour, and L. Korsakoff, J. Org. Chem. 1967, 32, 476476.

7. A. D. Adler, F.R. Longo, F. Kampas, and J. Kim, J. Inorg. Nucl. Chem. 1970, 32, 2443-2445.

8. Z. Dong, and P.J. Scammells, J. Org. Chem. 2007, 72, 9881-9885.

9. B. Chauvin, A. Kasselouri, P. Chaminade, R. Quiameso, I. Nicolis, P. Maillard, and P. Prognon, Anal. Chim. Acta 2011, 705, 306-314.

10. K. Lawson, J. Gross, and P.W. Crawford, Helv. Chim. Acta 2004, 87, 120-132.

11. P. Hambright, Chemistry of Water Soluble Porphyrins, in The Porphyrin Handbook, K.M. Kadish, K.M. Smith, and R. Guilard, Editors. 2000, Academic Press: New York. p. 129-210.

12. O. Ramirez-Gutierrez, J. Claret, and J.M. Ribo, J. Porph Phthalocyan. 2005, 9, 436-443.

13. A. Barbat, V. Gloaguen, V. Sol, and P. Krausz, Bioresource Technology 2010, 101, 6538-6544.

14. D.W. Dixon, A.F. Gill, L. Giribabu, A.N. Vzorov, A.B. Alam, and R.W. Compans, J. Inorg. Biochem. 2005, 99 , 813-821.

15. N. Carnieri, A. Harriman, G. Porter, and K. Kalyanasundaram, J. Chem. Soc. Dalton Trans. 1982, 1231-1238.

16. B. Winther-Jensen, and K. West, Macromolecules 2004, 37, 4538-4543.

17. C. Gu, B.C. Norris, F.-R.F. Fan, C.W. Bielawski, and A.J. Bard, ACS Catalysis 2012, 2, 746-750.

18. M. Fabretto, C. Jariego-Moncunill, J.-P. Autere, A. Michelmore, R.D. Short, and P. Murphy, Polymer 2011, 52, $1725-1730$

19. M. Fabretto, K. Zuber, C. Hall, and P. Murphy, Macromolecular Rapid Communications 2008, 29, $1403-1409$.

20. B. Winther-Jensen, J. Chen, K. West, and G. Wallace, Macromolecules 2004, 37, 5930-5935.

21. S.K. Andreas Elschner, W. Lövenich, U. Merker, and K. Reuter, PEDOT Principles and Applications of an Intrinsically Conductive Polymer, CRC Press, Boca Raton, 2011.

22. L. Groenendaal, F. Jonas, D. Freitag, H. Pielartzik, and J.R. Reynolds, Adv. Mater. 2000, 12, 481-494.

23. B. Winther-Jensen, and D.R. MacFarlane, Energy Environ. Sci. 2011, 4, 2790-2798.

24. C. Zhou, Z. Liu, Y. Yan, X. Du, Y.-W. Mai, and S. Ringer, Nanoscale Res. Lett. 2011, 6, 364.

25. Morehouse, K.M. and P. Neta, J. Phys. Chem. 1984, 88, 3118-3120.

26. Y. Tsuda, K. Takahashi, T. Yamaguchi, S. Matsui, and T. Komura, J. Mol. Catal. A Chem. 1998, 130, $285-295$.

27. L. J. Boucher, Coord. Chem. Rev. 1972, 7, 289-329.

28. F. Hibbert, and K.P.P. Hunte, J. Chem. Soc. Perkin Trans. 2 1977, 1624-1628.

29. C.J. Chang, Z.-H. Loh, Y. Deng, and D.G. Nocera, Inorg. Chem. 2003, 42, 8262-8269.

30. R. Chitta, L.M. Rogers, A. Wanklyn, P.A. Karr, P.K. Kahol, M.E. Zandler, and F. D'Souza, Inorg. Chem. 2004, 43, 6969-6978.

31. R.R. Durand, C.S. Bencosme, J.P. Collman, and F.C. Anson, J. Am. Chem. Soc. 1983, 105, 2710-2718.

32. E. Ojadi, R. Selzer, and H. Linschitz, J. Am. Chem. Soc. 1985, 107, 7783-7784.

33. A. Satake, Y. Kobuke, Org. Biomolec. Chem. 2007, 5, 1679-1691.

34. A. Harriman, G. Porter, J. Chem. Soc. Faraday Trans. 2: Mol. Chem. Physics 1979, 75, 1532-1542.

35. A. Harriman, G. Porter, J. Chem. Soc. Faraday Trans. 2: Mol. Chem. Physics 1979, 75, 1543-1552.

36. O. Horváth, Z. Valicsek, G. Harrach, G. Lendvay, and M.A. Fodor, Coord. Chem. Rev. 2012, 256, 1531-1545. 